\title{
HARDINESS IN THE STRUCTURE OF PERSONAL RESOURCES CONDUCIVE TO OVERCOMING PROFESSIONAL BURNOUT AMONG WORKERS DURING A PANDEMIC
}

\author{
Viktoriya I. Rerke ${ }^{1}$ \\ Natalia V. Belyakova ${ }^{2}$ \\ Angela B. Mottaeva ${ }^{3}$ \\ Lyudmila P. Shipovskaya ${ }^{4}$ \\ Alla V. Ignatyeva ${ }^{5}$ \\ Leonid V. Blinov ${ }^{6}$ \\ Irina G. Kalina ${ }^{7}$
}

\begin{abstract}
Today, the risk of emotional exhaustion is increasing and a decrease in the professional activity of healthcare workers is observed due to an epidemiologically unstable situation in the world. The importance and social significance of solving this problem is connected with the fact that the burnout
\end{abstract}

syndrome has a complex form and can be interpreted differently from the point of view of root causes and final outcome. This, in its turn, guides to the exploratory search for directions of psychological means and methods of influence. The purpose of the paper is to study hardiness in the structure of personal resources of

\footnotetext{
${ }^{1} \mathrm{PhD}$ in Psychology, Associate Professor of the Department of Social Pedagogy and Psychology, Irkutsk State University, Irkutsk, Russia. E-mail: rerkew@mail.ru. ORCID: https://orcid.org/0000-0002-77228287

${ }^{2} \mathrm{PhD}$ in Psychology, Associate Professor of the Faculty of Psychology, Russian State Social University, Moscow, Russia. E-mail: nbelyakova@mail.ru ORCID ID: https://orcid.org/0000-0001-7116-9389

${ }^{3}$ Doctor of Economics, Professor of the Department of Construction and Real Estate Management, Moscow State University of Civil Engineering, Moscow, Russia. E-mail: doptaganka@yandex.ru. ORCID: https://orcid.org/0000-0002-3599-5605

${ }^{4}$ Doctor of Philosophy, Associate Professor of the Department of Social Psychology, Moscow Automobile and Road Construction State Technical University (MADI), Moscow, Russia. E-mail: Shlp8@rambler.ru ORCID: https://orcid.org/0000-0001-6139-948X

${ }^{5} \mathrm{PhD}$ in Pedagogy, Associate Professor of the Department of Decorative Arts and Design, Moscow City University, Moscow, Russia. E-mail: alla.ignateva.66@inbox.ru. ORCID: https://orcid.org/0000-0001$7772-5219$

6 Doctor of Pedagogy, Professor of the Department of the Theory and Technique of Pedagogical and Defectology Education, Pacific National University, Khabarovsk, Russia. E-mail: astrax@list.ru. ORCID: https://orcid.org/0000-0003-0167-7147

${ }^{7} \mathrm{PhD}$ in Pedagogy, Associate Professor of the Department of Physical Education and Sport, Kazan Federal University Naberezhnye Chelny Institute, Naberezhnye Chelny, Russia. E-mail: KalinaIrinaGenn@yandex.ru. ORCID: https://orcid.org/0000-0003-0276-8227

*corresponding author email: rerkew@mail.ru
} 
overcoming professional burnout among healthcare workers during a pandemic. The leading techniques for the study of this problem were the following: psychodiagnostic technique "Diagnosis of emotional burnout", personality questionnaire, hardiness test. Hardiness has been studied in the structure of personal resources of overcoming professional burnout. The authors have proven that doctors possessing hardiness are distinguished by personal qualities that help them adapt and withstand difficult social situations. The features of professional burnout have been identified among healthcare workers during the Covid-19 pandemic. It has been found that a high level of hardiness in the structure of personal resources is a factor in overcoming professional burnout among doctors. The results obtained made it possible to develop practical recommendations to prevent professional burnout and boost hardiness among healthcare workers during the pandemic. The paper is intended for specialist psychologists, clinical psychologists, and healthcare managers.
Keywords: professional burnout, hardiness, healthcare workers, pandemic, personal resources.

\section{INTRODUCTION}

The current social situation reduces the feeling of safety and security of every person, and the situation of life threat is becoming more and more common in peaceful life (Kargapoltseva et al., 2019; Bayanova et al., 2019; Vinogradova et al., 2018; Quang et al., 2019; Caliskan et al., 2019).

The increased risk of emotional exhaustion and a decrease in professional activity among healthcare workers is of particular importance at the present time in an epidemiologically unstable situation in the world. Tremendous insurmountable strain is experienced by healthcare workers performing their professional activities in departments and hospitals providing treatment for Covid-19. The manifestation of professional strain is also caused by the main organizational preconditions: physical and psychological overload, the inability to control the social situation, the ambiguity of the standard in the algorithm of actions of the doctor and 
nursing staff, double standards of material reward for working with Covid19 patients. For this reason, the importance of seeking personal resources from medical professionals is crucial.

The importance and social significance of solving this problem is connected with the fact that the burnout syndrome has a complex form, and it is interpreted differently from the point of view of root causes and final outcome. This, in its turn, guides to the exploratory search for directions of psychological means and methods of influence.

In this regard, the study of the possibilities and role of psychological resources is of scientific and practical interest to understand how strain and the global situation of a pandemic affect people. Domestic and foreign researchers (Leontiev \& Rasskazova, 2006; Maddi, 2005; Hobfall, 1998) are interested in searching for human forces and resources that will contribute to the leveling of negative social consequences.

The methodological foundation of the study is based on the principles of the unity of consciousness and activity (Rubinstein, 2016), an individual's personality development in activity
(Vygotsky, 2014; Lomov, 2013). In addition, in our study we relied on the works on the problems of professional burnout (Boiko, 2001; Maslach, 1986), as well as on the works of the phenomenon of hardiness as a resource of an individual (Maddi, 2005; Vasilyuk, 1984).

We need to have a look at the definition of "resources" in psychology. In the broadest interpretation, the concept of "resources" is an integral part of the personal and human reserve (Zarakovsky \& Stepanova, 1998; Kagan, 1974). A number of authors (Abulkhanova, 2017; Antsyferova, 2006; Salakhova \& Rerke, 2019; Rerkea, Salakhova \& Ignatov, 2020) consider resources in the context of life strategies.

With such understanding of this term, it is worth taking into account that resources are also opportunities, and the means by which one can cope with stress (Bodrov, 2006; Lazarus, 1989; Hobfall, 1998), as well as resources - there is a basis for self-regulation of behavior and activity (Muzdybaev, 1998; Osnitsky, 1992; Ivanova et al., 2018; Pankova, 2015; Rukavishnikov \& Sokolova, 2002).

Personality resources embrace attitudes and motives that affect the 
ability to regulate behavior in stressful situations. It is worth attributing the following to the most significant qualities: self-control of behavior, selfesteem of the individual, self-respect, optimism and motivation (Bodrov, 2006).

In the situation of a pandemic, the search for personality resources is of particular interest that will allow coping with stressful situations, namely, selfmotivation for coping with stress and strain, a positive attitude to stress as an opportunity for personal and professional growth; strengthening of the components "I - concept"; an active life position; critical thinking and rationality of thinking; volitional qualities of the individual, as well as the value and meaning attitude to the resources of physical health (NartovaBochaver, 2009).

The mechanisms of adaptation to psychological, physiological strain, focusing on the professional competence of a doctor in a pandemic situation dictate the formation of new interdisciplinary problem-solving skills. It is worth noting that healthcare workers are characterized by the presence of such personality traits that help professionally fulfill themselves in difficult life situations: realistic thinking and perception, professional, well-formed life-meaning orientations; originality of thinking and achievement of goals. The possession and manifestation of these personal qualities increases vitality, hardiness and adaptation to life circumstances (Stukalova et al., 2018; Faleeva et al., 2017; Razumovskaya et al., 2018; Ezhov et al., 2019; Latysheva et al., 2018; Masalimova et al., 2017).

The purpose of the paper is to study hardiness in the structure of personal resources that are conducive to overcoming professional burnout among healthcare workers during a pandemic.

\section{MATERIALS AND METHODS}

The study undertaken to explore hardiness in the structure of personal resources of professional burnout among healthcare workers during the Covid-19 pandemic was carried out in hospitals of Irkutsk and Ulyanovsk in the period from April to December 2020. The total sample size was 250 healthcare workers, the mean age of the subjects was 41.3 years.

In the course of the study, the following methods were used: the technique "Diagnostics of emotional 
burnout" by V.V. Boiko (2001), personality questionnaire by $\mathrm{R}$. Cattell (2002), the hardiness test proposed by D.A. Leontiev and E.I. Rasskazova (2006). Methods of mathematical statistics (Pearson correlation coefficient) were used to determine the reliability and significance of differences.

The first diagnostic tool used by us was the technique "Diagnostics of emotional burnout" by V.V. Boiko (2001). Its goal is to study the level of manifestation of emotional burnout. The second diagnostic tool used by us was R. Cattell's personality questionnaire (2002). In our work, we used the full version of the technique (form B). The third diagnostic tool used by us was the hardiness test, developed by D.A. Leontiev and E.I. Rasskazova (2006).

\section{RESULTS AND DISCUSSION}

In the course of the research work on the study of hardiness in the structure of personal resources of overcoming professional burnout among healthcare workers during the pandemic, the following results were obtained.

The indicators of the manifestation of emotional burnout symptoms and phases among healthcare workers of this sample are clearly presented in Tables 1 and 2 .

Table 1. Indicators of symptoms in the phases of emotional burnout among healthcare workers (in \%)

\begin{tabular}{|c|c|c|c|c|}
\hline Symptoms of the emotional burnout phases & 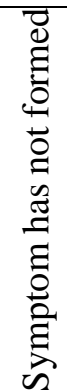 & 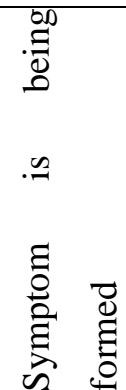 & 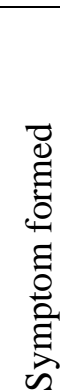 & 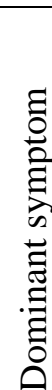 \\
\hline \multicolumn{5}{|l|}{ Strain } \\
\hline Experiencing psychotraumatic circumstances & 47 & 21 & 28 & 8 \\
\hline Self-dissatisfaction & 74 & 21 & - & 8 \\
\hline Anxiety-depressive symptom & 81 & 21 & - & - \\
\hline Depression & 61 & 28 & 14 & - \\
\hline
\end{tabular}




\begin{tabular}{|l|l|l|l|l|}
\hline Inadequate selective emotional response & 7 & 20 & 20 & 53 \\
\hline Emotional and moral disorientation & 13 & 47 & 33 & 7 \\
\hline $\begin{array}{l}\text { Expansion of the sphere of economization of } \\
\text { emotions }\end{array}$ & 40 & - & 7 & 53 \\
\hline Reduction of professional duties & 27 & 13 & 40 & 20 \\
\hline Exhaustion & 46 & 40 & 7 & 7 \\
\hline Emotional deficit & 47 & 33 & 7 & 13 \\
\hline Emotional detachment & 73 & 20 & 7 & - \\
\hline Personal detachment (depersonalization) & 60 & 26 & 7 & 7 \\
\hline $\begin{array}{l}\text { Psychosomatic and psychovegetative } \\
\text { disorders }\end{array}$ & & & & \\
\hline
\end{tabular}

The results of the data obtained (Table 2) indicate that the majority of healthcare workers in this sample did not develop symptoms in the strain phase. Such a symptom as psychological shock in professional activity is difficult to eliminate. This symptom develops in $21 \%$ of healthcare workers and has formed in $28 \%$ of healthcare workers in this sample, while in $8 \%$ of healthcare workers this symptom is dominant, they have a pronounced experience of psychotraumatic factors of professional activity. Manifestations of a negative attitude towards themselves, towards their professional activities, towards specific job responsibilities were found in $28 \%$ of healthcare workers in this sample. A symptom of selfdissatisfaction arising in $21 \%$ of healthcare workers, this condition is assessed by respondents as hopeless, it manifests itself at the intellectual and emotional level as a deadlock. At the same time, a symptom of disappointment in themselves and their profession develops in $28 \%$ of healthcare workers and it has formed in $14 \%$ of healthcare workers.

In the phase "resistance", such symptoms as painful emotional response (53\% of healthcare workers) and economization of emotions $(53 \%$ of healthcare workers) are the dominant ones. The psychological defense mechanisms are activated, which are manifested in the inadequate selective reaction of doctors. Namely, there is a decline in communication with colleagues during working hours on 
professional issues, in the future, the weakening of communications is transferred to interaction with family members. In this regard, we state that emotional and moral disorientation has formed in $33 \%$ of healthcare workers. And the mechanism of reducing professional obligations is typical of $40 \%$ of healthcare workers.

In the phase "exhaustion", which dominates in $13 \%$ of healthcare workers, there is a sense of detachment from emotions and a lack of empathy. The symptom of a lack of emotions and feelings began to develop in $40 \%$ of healthcare workers. The subjects note that they are psycho-emotionally shattered and this tells on their intellectual and moral-volitional sphere.

The symptom of personal isolation and the symptom of somatic and autonomic disorders did not develop or they were just beginning to develop among the healthcare workers of this sample in the "exhaustion" phase. However, in $7 \%$ of healthcare workers, these symptoms dominate, which indicates an exacerbation of concomitant somatic diseases, which are a consequence of professional burnout.

Next, we describe the generalized data for each symptom in the phases of burnout and highlight the levels of formation of each phase (Table 2).

Table 2. Specific features of the phase formation of emotional burnout among healthcare workers (in \%)

\begin{tabular}{|l|l|l|l|}
\hline $\begin{array}{l}\text { Degree of expressiveness of the emotional } \\
\text { burnout phases }\end{array}$ & Strain & Resistance & Exhaustion \\
\hline The phase has not formed & 63 & 5 & 50 \\
\hline The phase is being formed & 28 & 40 & 40 \\
\hline The formed phase & 9 & 55 & 10 \\
\hline
\end{tabular}

As we can see from Table 2, the majority of healthcare workers did not develop the "strain" phase $(63 \%$ of the subjects), the "resistance" phase was formed (53\% of the respondents) and it is in the stage of formation $(40 \%$ of the subjects), the "exhaustion" phase also 
did not form $(50 \%$ of healthcare workers).

For doctors in this sample, the strain of anxiety is not a sign and a pretrigger mechanism of professional burnout (63\% of respondents). For this group of subjects, the experience of traumatic factors in professional activity is not characteristic, these doctors are satisfied with themselves and do not show anxiety. In 9\% of healthcare workers the stage of emotional burnout "strain" is formed, which indicates the initial stage of emotional burnout in nurses. In $28 \%$ of healthcare workers, the formation of the stage of "strain" is observed, which is expressed in the manifestation of symptoms such as selfdissatisfaction, anxiety and depression.

At the same time, $55 \%$ of healthcare workers have formed the phase of "resistance", which manifests itself in an emotional reaction that does not correspond to the norm, emotional disorder; emotional decline and weakening of professional duties. In $40 \%$ of healthcare workers, the phase of emotional burnout "resistance" is at the stage of formation, which is manifested in an inadequate emotional response, disorientation of the individual's personality at the level of morality and ethics; the area of economization of emotions and emotional manifestations is growing. In $9 \%$ of healthcare workers, this phase is not formed, therefore, such subjects have psychological resources that allow them to weaken external pressure.

Empirical data on the formation of the emotional burnout phase "exhaustion" in healthcare workers indicate that $55 \%$ of healthcare workers have not formed a phase, a decrease in vital activity is not characteristic of such subjects, a normal emotional reaction to external stimuli is observed among them. In $40 \%$ of healthcare workers, the emotional burnout phase "exhaustion" is formed, which manifests itself in the weakening of vital functions, in psychological defense. Whereas $9 \%$ of healthcare workers in this sample developed the emotional burnout phase of "exhaustion", which indicates a decrease in the energy tone of healthcare workers and weakening of the nervous system.

Personal resources of overcoming professional burnout of healthcare workers during the pandemic are presented in the personal profile in Figure 1. 


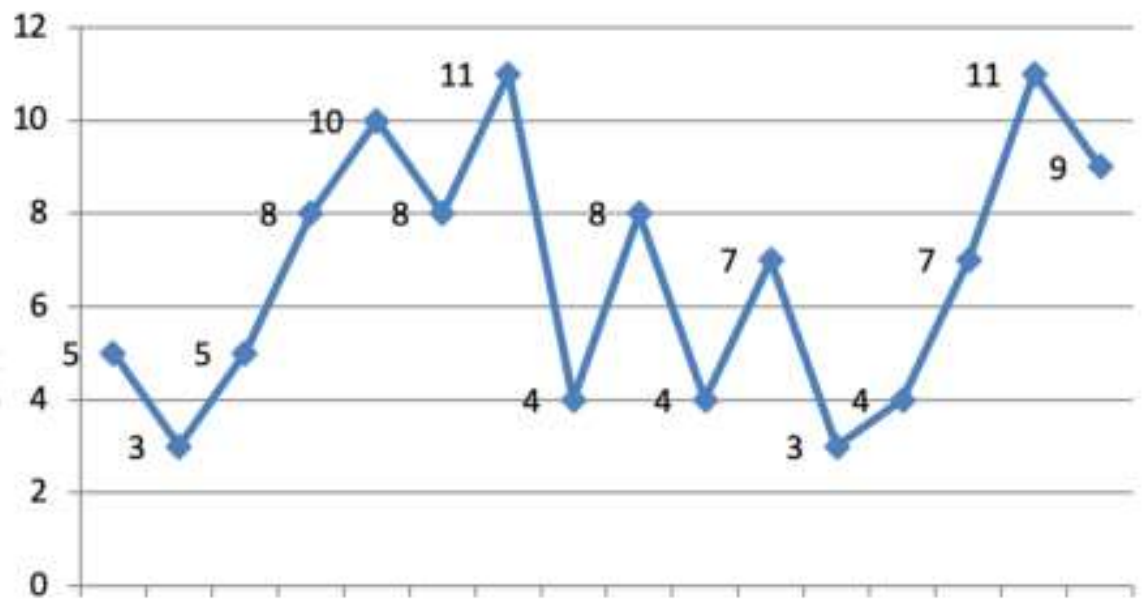

Factors

$\begin{array}{llllllllllllllll}\text { A } & \text { B } & \text { C } & \text { E } & \text { F } & \text { G } & \text { H } & \text { I } & \text { L } & \text { M } & \text { N } & \text { O } & \text { Q1 } & \text { Q2 } & \text { Q3 } & \text { Q4 }\end{array}$

Figure 1. Personality profile of healthcare workers (average scores)

The analysis of the data in

Figure 1 allows us to draw a psychological portrait of healthcare workers' personality and to identify personal resources of overcoming professional burnout.

According to factor A, healthcare workers are characterized by caution, isolation, suspicion, and the difficulty of establishing interpersonal contacts. Such characteristics may be a consequence of the beginning of the process of professional burnout or, on the contrary, may cause it.

Factor B indicators reflect such characteristics of healthcare workers as accuracy and some stiffness of thinking, the complexity of solving abstract problems, and an insufficient level of communicative culture.

It is important to note the instability in the manifestations of emotions, some affectivity, inconstancy in interests and asthenia. Such characteristics may be a consequence of the onset of professional deformation of the personality of healthcare workers and reflect, in our opinion, the initial stage of professional burnout of the individual's personality.

The healthcare workers of this sample are distinguished by autonomy, independence, firmness and hardiness, totalitarianism. Obstinacy, independence and a certain amount of stubbornness can act as a personal resource for 
overcoming professional burnout, as it reflects the active and independent position of healthcare workers (factor E).

Optimism, liveliness and mirth imply emotional leadership in groups; these qualities also act as a resource for the individual and help overcome professional burnout (factor F).

Factor $\mathrm{G}$ indicators also allow us to single out them as a personal resource for overcoming professional burnout. Healthcare workers are characterized by high behavioral standards, reliability in relation to these obligations.

Determination, initiative and resourcefulness, businesslike approach and activity - these characteristics of healthcare workers can also act as a personal resource to overcome professional burnout.

Low indicators for factor I indicate pragmatism and unconditional nature of healthcare workers.

Secrecy, egoism, alienation from colleagues and people around such indicators, in our opinion, may indicate the initial stage of emotional burnout of their personality, its destructiveness.

The practical approach of healthcare workers is a personal resource of overcoming professional burnout. The respondents are distinguished by mobility in decision-making, realism and pragmatism.

Pronounced diplomacy according to factor $\mathrm{N}$ is a personal resource of overcoming professional burnout and reflects such characteristics of healthcare workers as correctness in relationships, self-control, observation and sagacity of the mind, the ability to find a way out of difficult situations.

According to the $\mathrm{O}$ factor, healthcare workers are characterized by serenity, arrogance, cheerfulness, selfconfidence and self-reliance, carelessness.

Indicators of factor Q2 show us the manifestation of opposition, negativism, orientation towards their own decisions among healthcare workers. Such characteristics act as a personal resource that helps overcome professional burnout in healthcare workers.

High scores on the Q4 factor reflect discipline, self-organization, and leadership of healthcare workers.

Thus, the personal resources for overcoming professional burnout in this sample of healthcare workers can be such characteristics as dominance, 
expressiveness, high normative behavior, courage, practical approach, diplomacy, non-conformity, high selfcontrol and tension.
The features of hardiness among healthcare workers are presented in Table 3.

Table 3. Hardiness indicators of healthcare workers (average scores)

\begin{tabular}{|l|l|l|}
\hline Parameters of hardiness & Sample & Mean values \\
\hline Hardiness & 81,67 & $81,72(+-18,49)$ \\
\hline Commitment & 39,08 & $39,64(+-8,11)$ \\
\hline Control & 28,45 & $30,18(+-8,51)$ \\
\hline Challenge & 15,37 & $15,97(+-5,02)$ \\
\hline
\end{tabular}

The analysis of the data in Table 3 makes it possible to conclude that the healthcare workers in this sample are distinguished by moderately expressed indicators of hardiness. Healthcare workers in this sample are distinguished by a rather pronounced activity and dynamism of an individual's personality. Healthcare professionals apply the methods of positive psychotherapy in practice. Thus, we can say that moderately expressed indicators of hardiness can serve as a factor in overcoming professional burnout.

Next, we compared the obtained diagnostic data using the methods of mathematical statistics (Pearson's correlation coefficient) to identify the correlation indicators of the relationship between hardiness as a personal resource and professional burnout of healthcare workers (Table 4).

Table 4. Correlation indicators of the relationship between hardiness as a personal resource and professional burnout of healthcare workers

\begin{tabular}{|c|c|c|c|c|c|c|c|}
\hline Parameters & $\begin{array}{l}\text { : } \\
\text { 节 }\end{array}$ & 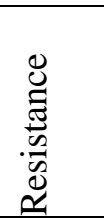 & 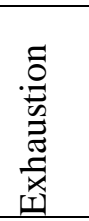 & 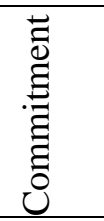 & $\begin{array}{l}\overline{0} \\
\text { : } \\
\text { ¿ }\end{array}$ & $\begin{array}{l}\stackrel{0}{\infty} \\
\stackrel{\Xi}{0} \\
\bar{\Xi} \\
\stackrel{\Xi}{U}\end{array}$ & 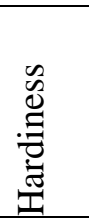 \\
\hline Strain & $*$ & $0,75^{*}$ & 0,33 & $-0,11$ & $-0,37$ & $-0,42$ & $-0,33$ \\
\hline
\end{tabular}




\begin{tabular}{|l|l|l|l|l|l|l|l|}
\hline Resistance & & $*$ & $0,58^{*}$ & $-0,27$ & $-0,21$ & $-0,46$ & $-0,33$ \\
\hline Exhaustion & & & $*$ & $-0,51^{*}$ & $-0,37$ & $-0,78^{*}$ & $-0,58^{*}$ \\
\hline Commitment & & & & $*$ & $0,63^{*}$ & 0,43 & $0,85^{*}$ \\
\hline Control & & & & & $*$ & $0,67 *$ & $0,93^{*}$ \\
\hline Challenge & & & & & & $*$ & $0,76^{*}$ \\
\hline Hardiness & & & & & & & $*$ \\
\hline
\end{tabular}

Note: * significant correlations are marked with an asterisk

The analysis of the data presented in the table allows us to speak about the existence of positive and negative relationships between indicators of hardiness as a personal resource and professional burnout of healthcare workers.

So, the more the nervous (anxious) strain is expressed in healthcare workers, the more inadequate emotional response, emotional and moral disorientation, the expansion of the economization of emotional reactions, the weakening of the scope of professional duties $(r=0.75)$.

At the same time, the more healthcare workers show the inconsistency of emotional manifestations with life situations, the disorder of the emotional and moral spheres, and a decrease in vital activity ( $\mathrm{r}$ $=0.58)$.
The higher the weakening of vital activity in healthcare workers is, the less pronounced such characteristics of hardiness as commitment $(\mathrm{r}=-0.51)$, challenge $(r=-0.78)$ and general level of hardiness $(r=-0.58)$.

The higher the commitment of healthcare workers is, the more pronounced their control $(\mathrm{r}=0.63)$ and the general level of hardiness $(r=0.85)$. At the same time, a high level of control ensures challenge $(r=0.67)$ and general level of hardiness expressiveness $(r=$ 0.93). At the same time, the more pronounced the challenge, the higher the level of hardiness expressiveness $(\mathrm{r}=$ $0.76)$.

The analysis of the data obtained confirms the assumption that a high level of hardiness in the structure of personal resources serves as a factor in overcoming professional burnout (to be specified after the study). 


\section{Recommendations}

The study of professional burnout and hardiness in the structure of personal resources of healthcare workers during a pandemic, undertaken by the authors, made it possible to formulate a number of organizational directions for overcoming the syndrome of professional and emotional exhaustion:

- conceptual stage distribution of functional responsibilities between doctors and healthcare workers of Covid departments and hospitals; the formation of a common goal, objectives, meanings of cooperation;

- project and diagnostic stage - an examination of the psychological state of healthcare workers on the basis of existing criteria; monitoring the effectiveness of the treatment process, taking account of the identified conditions;

- activity stage - creating conditions for interaction between healthcare workers and a clinical psychologist, counseling psychologist, psychotherapist to determine the reasons and directions for resolving psychological difficulties;

- introspective diagnostic stage - the final diagnostics based on the results of counseling; subjective assessment of the psychological state of healthcare workers.

\section{CONCLUSION}

The quantitative and qualitative interpretation of the results of the study that has been carried out allows us to draw the following conclusions:

1. The "strain" phase has not formed in the majority of healthcare workers, (63\% of the subjects), the "resistance" phase has formed (55\% of the respondents) and is in the stage of formation ( $40 \%$ of the subjects), the "exhaustion" phase has not formed either (50\% of healthcare workers). Among healthcare workers in this sample, anxiety is not the forerunner and trigger mechanism in the formation of emotional burnout, the strain is not mobile, and this fact does not lead to 
exhausting constancy or an increase in psycho-traumatic factors $(63,6 \%$ of respondents). At the same time, 55\% of healthcare workers have developed the phase of "resistance", which manifests itself in inadequate emotional response, emotional and moral disorientation; expanding the sphere of economization of emotions, reducing professional responsibilities. The data on the formation of the "exhaustion" phase of emotional burnout among healthcare workers indicate that $55 \%$ of healthcare workers have not developed this phase; a drop in the general level of vital activity is not typical of such subjects.

2. The personal resources for overcoming professional burnout in healthcare workers of this sample can be such characteristics as dominance, expressiveness, high standard behavior, courage, practical approach, diplomacy, non-conformity, high self-control and strain.

3. Healthcare workers of this sample are distinguished by autonomy, independence, firmness and hardiness, totalitarianism. Obstinacy, independence and a certain amount of stubbornness can be a personal resource for overcoming professional burnout, as it reflects the active and independent position of healthcare workers.

4. The analysis of the data obtained confirms the assumption that a high level of hardiness in the structure of personal resources is a factor in overcoming professional burnout (to be specified after the study). The decrease in vital activity and activity, the weakening of the nervous system are higher among healthcare workers, when such characteristics of hardiness as commitment $(r=-0.51)$, challenge $(r=-$ 0.78) and the general level of hardiness $(\mathrm{r}=-0,58)$ are less pronounced.

\section{References}

Abulkhanova, K.A. Time of personality and its life path. Institute of Psychology of the Russian Academy of Sciences. Man and the World, 1(1), 165-200. (2017).

Antsyferova, L.I. Personality development and problems of gerontopsychology. Moscow: Institute of Psychology RAS. (2006).

Bayanova, A.R, Sabaeva, E.K., Sakhipova, Z.M., Zatsepina, M.B., Tararina, L.I., Votinov, A.A. \& Ilkevich, K.B. Educational Environment Ecology as Factor of University Teacher Health Saving in Context of Education and 
Science Reforms in Modern Russia. Ekoloji, 28(107), 4937-4941. (2019).

Bodrov, V.A. The problem of overcoming stress. Part 3. Strategies and styles of coping with stress. Journal of Psychology, 27(3), 106-116. (2006).

Boiko, V.V. Diagnostics of the level of emotional burnout. Practical psychodiagnostics. Methodology and tests. Samara: Bakhrakh-M. (2001).

Caliskan, S., Guney, Z., Sakhieva, R.G., Vasbieva, D.G., \& Zaitseva, N.A. Teachers' Views on the Availability of Web 2.0 Tools in Education. International journal of emerging technologies in learning, 14(22), 70-81. (2019).

Ezhov, K.S., Cherdymova, E.I., Prokopyev, A.I., Fabrikov, M.S., Dorokhov, N.I., Serebrennikova, Y.V., Belousov, A.L. \& Efimova, O.S. Conflict features depending on stay duration at workplace. Dilemas contemporáneos: Educación, Política y Valores, VI (Special Edition), Article No: 38. (2019).

Faleeva, L.V., Bratukhina, E.V., Ezhov, S.G., Gorbunova, L.N., Lopanova, A.P., Viaznikova, L.F. \& Kryukova, N.I. Student's Social Experience Forming in University Vocational Training.
Eurasian Journal of Analytical Chemistry, 12(7B), 1127-1135. (2017).

Hobfall, S. Stress, Culture and Communication. St. Petersburg: Speech. (1998).

Ivanova, T.Yu., Leontiev, D.A., Osin, E.N., Rasskazova, E.I. \& Kosheleva, N.V. Modern problems of studying personal resources in professional activity. Organizational psychology, 1. URL:

https://cyberleninka.ru/article/n/sovrem ennye-problemy-izucheniyalichnostnyh-resursov-vprofessionalnoy-deyatelnosti (date of access: 05/30/2020). (2018).

Kagan, M.S. Human activity. Moscow: Politizdat. (1974).

Kargapoltseva, N.A., Rakhimova, O.N., Shabalina, L.G., Guryanova, T.Y., Mashkin, N.A., Mirzalimov, R.M. \& Popova, N.F. Student Identity and Various Procedures of its Development. International Journal of Applied Exercise Physiology, 2, 519-526. (2019). Latysheva, V.V., Bulgakova, V.O., Sidorenko, G.G., Korenko, Ju.M., Khairullina, E.R. \& Shaidullina, A.R., Bayanova, A.R. Subjective Environmental Attitude Features to Nature of Specially Protected Areas 
Employees. Ekoloji, 27(106), 18011808(2018).

Lazarus, R. Individual sensitivity and resistance to psychological stress. Psychological factors at work and health protection. Moscow: Geneva. (1989).

Leontiev, D.A. \& Rasskazova, E.I. Resilience Test. Moscow: Meaning. (2006).

Lomov, B.F. Methodological and theoretical problems of psychology. Moscow: Directmedia. (2013).

Maddi, S.P. Formation of meaning in decision making. Psychological Journal, 26(6): 87-101. (2005).

Masalimova, A.R., Shagieva, R.V., Kosarenko, N.N., Latysheva, Z.I., Khairullina, E.R. \& Vyatkina, I.V. The Russian experience of subject-subject interaction between university teachers and students on the basis of drama in education. Modern Journal of Language Teaching Methods, 7(2): 177-185(2017). Maslach, C. Maslach burnout inventory. Consulting psychologists press, 21, 3463-3464. (1986).

Muzdybaev, K. Strategy for coping with life's difficulties. Theoretical analysis. Journal of Sociology and Social Anthropology, 1(2), 102-112. (1998).

Nartova-Bochaver, S.K. The unity of the subject and being as the basis of natural psychotherapy. Subjective approach in psychology. Moscow: Institute of Psychology RAS. (2009).

Osnitsky, A.K. Skills of self-regulation in the professional self-determination of students. Psychology Questions, 1(2), 52-59. (1992).

Pankova, A.A. Theoretical and methodological foundations of the study of the problem of life prospects in domestic and foreign psychology and pedagogy. Science and education today, 1.

URL:

https://cyberleninka.ru/article/n/teoretik o-metodologicheskie-osnovaniyaissledovaniya-problemy-zhiznennoyperspektivy-v-otechestvennoy-izarubezhnoy-psihologii-i (date of access: 05.30.2020). (2015).

Quang, H.N., Kosarenko, N.N., Khairullina, E.R. \& Popova, O.V. The Relationship between the State and the Catholic Church in Postcolonial Vietnam: The Case of Christian Village of Phung Khoang. Theological Quarterly, 79(2)m 521-533. (2019).

Razumovskaya, M.I., Larionova, A.A., Zaitseva, N.A., Orekhov, V.D., Trufanova, S.N., Korzhanova, A.A., \& Takhumova, O. Modeling the network integration space for educational 
programs. Modern journal of language teaching methods, 8(5), 56-67. (2018).

Rerke, V.I., Salakhova, V.B. \& Ignatov, S.B. Formation and development of resilience among teachers of higher educational and professional institutions through interactive forms of interaction. Personality Formation, 1, 107-118. (2020).

Rubinstein, S.L. Being and consciousness. St. Petersburg. Publishing house "Peter".(2016).

Rukavishnikov, A.A. \& Sokolova, M.V. Factorial personal questionnaire of $\mathrm{R}$. Cattell: methodological guidance. St. Petersburg: State Enterprise 'Imaton'. (2002).

Salakhova, V.B. \& Rerke, V.I. The value-semantic aspect of the resilience of the individual: the problem of adaptation in the penitentiary system. Personality Formation, 3(4), 164-170. (2019).

Stukalova, O.V., Akhmadieva, R.S., Khasyanov, O.R., Faleeva, L.V., Ashrafullina, G.S., Fortova, L.K., Kochneva, L.V. \& Kryukova, N.I. Modern Trends in Educational Institutions Education Quality Assessment. Modern Journal of Language Teaching Methods, 8(9), 197208. (2018).
Vasilyuk, F.E. Psychology of experience. Moscow: MSU Publishing House. (1984).

Vinogradova, G.A., Akhmadieva, R.Sh., Konovalova, V.M., Spirina, E.V., Kalugina, O.A., Erdyneeva, K.G., Popova, N.N. \& Mashkin, N.A. Releasers as Factor of Student Ecological Focus Formation. Ekoloji, 27(106), 1409-1415. (2018).

Vygotsky, L.S. Thinking and speech. Moscow: Directmedia. (2014).

Zarakovsky, G.M. \& Stepanova, G.B. Psychological potential of the individual and the population. Man, 3, 50-59. (1998). 